\section{Dietary assessment in the 1993 Pelotas (Brazil) birth cohort study: comparing energy intake with energy expenditure}

\author{
Avaliação dietética da coorte de nascimentos \\ de Pelotas, Rio Grande do Sul, Brasil, 1993: \\ uma comparação da ingestão e do \\ gasto de energia
}

\begin{abstract}
${ }^{1}$ Faculdade de Nutrição, Universidade Federal de Pelotas, Pelotas, Brasil. 2 Escola Superior de Educação Física Universidade Federal de Pelotas, Pelotas, Brasil. 3 Programa de Pós-graduação em Educação Física, Universidade Federal de Pelotas, Pelotas, Brasil.

${ }_{4}$ Programa de Pós-graduação em Epidemiologia,

Universidade Federal de Pelotas, Pelotas, Brasil. 5 Faculdade de Medicina, Universidade Federal do Rio Grande do Sul, Porto Alegre, Brasil.

${ }^{6}$ Faculdade de Medicina, Universidade Federal de Pelotas, Pelotas, Brasil.

Correspondence D. P. Gigante

Departamento de Nutrição,

The studyaims to describe and compare two methods of energy intake assessment and one measure of energy expenditure applied in adolescents from a birth cohort. In a sub-sample of the 1993 Pelotas (Brazil) birth cohort, followed up in 2006-7, information on intake was obtained through a food-frequency questionnaire (FFQ) and three 24-hour-recalls (24hR), while energy expenditure was assessed using an accelerometer. Bland \& Altman plots were used in the analyses in order to compare the methods. The mean difference between FFQ and 24hR was $592 \pm 929 \mathrm{cal} /$ day. Compared to energy expenditure, intake was overestimated when measured by FFQ (357 $\pm 968 \mathrm{cal} /$ day $)$ and underestimated by $24 \mathrm{hR}(-278 \pm 714$ cal/day $)$. In spite of the great differences between energy intake obtained using the two methods, lower differences were observed when these methods were compared to expenditure.
\end{abstract} Faculdade de Nutrição, Universidade Federal de Pelotas.

C. P. 354, Campus

Universitário, Pelotas, RS

96010-900, Brasil.

denise.gigante@terra.com.br

Energy Intake; Adolescent Nutrition; Energy Metabolism; Validation Studies

\author{
Denise P. Gigante 1 \\ Felipe Fossati Reichert 2,3 \\ Pedro C. Hallal 3,4 \\ Rosângela Velleda de Souza 1 \\ Marilda Borges Neutzling 5 \\ Maria de Fátima Alves Vieira 1 \\ Maria Cecilia Formoso Assunção 1 \\ Cora Luiza Araújo 1 \\ Ana M. B. Menezes 6
}

\section{Introduction}

A challenge in nutritional epidemiology is to measure accurately food intake. Different methods are used in dietary assessment, but errors are inherent in all of these methods 1 . In epidemiology, the process used to assess measurement errors is known as validity. A measure is valid or accurate if the figure found is close to the true value. In nutritional epidemiology, however, this process is challenging, because it is unlikely that a single instrument will provide "gold standard" information on the intake of foods or nutrients.

Comparisons among different methods of dietary assessment, including reliability and reproducibility of measurements, have been conducted in several studies, mainly from high income countries, and summarized in review studies 2,3 . The conclusion of all these studies is that each method presents a margin of bias and none may be considered as a gold standard. In addition, while some methods investigate food intake over a one-day period, others assess the usual intake of foods. So, the validation process of energy intake has been compared using external methods such as: (a) energy required maintaining weight; (b) measured energy expenditure; (c) presumed energy requirements, expressed as multiples of basal metabolic rate. The three comparison methods are based on the assumption that energy intake is equal to energy expenditure when weight is stable. To sum up, 
the validation process of energy intake should include different methods of dietary assessment and other techniques such as external measurements or biomarkers 3 .

The direct comparison of energy intake and expenditure allows the assessment of measurement errors and the doubly labeled water (DLW) technique has been considered as a gold standard for measuring energy expenditure under realistic daily conditions. Given that DLW is expensive and only available to a few research centers, alternative methods for measuring energy expenditure (heart-rate monitoring, accelerometers or physical activity questionnaires) may also be used to validate reported energy intake. Considering the limitation of reported physical activity through questionnaires and the high cost of DLW, accelerometry has become the method of choice for objectively measuring physical activity in free-living adolescents 4 , taking into account that the accelerometer shows reasonable concordance with DLW for measuring daily energy expenditure 5 .

In the present study, the main objective is to describe and compare two methods of energy intake assessment and one measure of energy expenditure applied in adolescents from a birth cohort study. Energy intake estimated from two instruments is compared with energy expenditure measured by accelerometry.

\section{Methods}

In 1993, all 5,265 births in the maternity wards of the city of Pelotas in Southern Brazil were identified and 5,249 mothers accepted to participate in a cohort study. A subsample of these mothers was followed up along the first five years of life of the children. When the cohort's members were aged 11 (2004-2005), the whole cohort was visited. In the following year, a subsample with data available for all waves of data collection was sought for a detailed study on physical activity and body composition. Further information on the 1993 Pelotas (Brazil) birth cohort study is presented in another set of literature 6,7.

For the present analyses, we randomly selected 63 subjects from each tercile of socioeconomic status as in the 2004-2005 follow-up, representing one third of the subsample included in the physical activity and body composition study ${ }^{8}$. Therefore, 189 adolescents were selected to participate in the energy intake study. This sample was calculated based on a difference of 500 calories between the two methods, a standard deviation of 1,000 calories with $90 \%$ power, $95 \%$ confidence level, and an addition of $10 \%$ for losses 9. The sample size was also sufficient to find a difference of 400 calories with $80 \%$ power and the same other parameters.

Data collection was conducted between the second semester of 2006 and the first semester of 2007. A food frequency questionnaire (FFQ) and three 24 -hour-recalls (24hR) were applied by four nutritionists trained in these methods. The interviews were carried out in the subjects' home, preferentially in the kitchen, and the questionnaires were applied to the adolescent. Questions about some details of the recipes and cooking methods were also put to the person who usually prepares the meals. All recalls and questionnaire were checked before and after data entry of food composition by a fieldwork supervisor who was a nutritionist.

The interview to apply the first $24 \mathrm{hR}$ was scheduled on Friday followed by the Wednesday on which each adolescent started to wear the accelerometer. In the following week, the other two $24 \mathrm{hR}$ were carried out on one weekend day (Sunday) and another week day (Wednesday). On Thursday, the FFQ was also applied.

The ActiGraph accelerometer (model GT1M; LLC, Pensacola, USA), a motion sensor, was placed on the left side of the waist to determine physical activity measured by counts per minute (cpm). Adolescents wore the accelerometers from Wednesday to Monday and they were encouraged to wear them 24 hours per day, except when showering, bathing or swimming. An instruction sheet with a brief description of the device, details of how to wear, and contact information was left with the adolescent at the first visit. This instruction sheet also had a diary for the devices and the subjects were instructed to note if they did not wear the monitors for any period longer than one hour during the day. Usually on the Monday morning, a field-worker visited each adolescent's house to collect the monitor and the diary. After this, data from the accelerometers were downloaded and the devices were placed on battery chargers. On Tuesday the recharged monitors were set up for another adolescent.

The study was approved by the Ethics Committee at the Medical School of the Federal University of Pelotas. Written informed consent was obtained from parents or guardians prior to adolescent participation.

The FFQ included 72 foods/drinks according to a previous study with Brazilian adolescents 10 . Energy intake estimated from FFQ was calculated multiplying each food/drink declared frequency (daily, weekly, monthly or annually) by the caloric content of a standard portion for that food item, summing up the caloric content from all items declared in the questionnaire, and pre- 
sented in daily energy intake. The standard portion sizes were determined by the mean amount obtained from the $24 \mathrm{hR}$ applied in adolescents from Pelotas private schools and the recall period was one year.

The 24hR captured in detail all foods/drinks including recipes, in case of prepared food, cooking methods and all portion size as consumed. The amount of food/drink was recorded using local serving utensils. A digital scale and a standard cup were used by the nutritionists to weigh and to measure foods and drinks in grams or milliliters, respectively, as needed and available. Pictures of fruits and vegetables with known amounts in grams were also used if the item was unavailable in the adolescent's home.

Energy intake was calculated using the Brazilian Food Composition Table (TACO, version 2. Núcleo de Estudos e Pesquisas em Alimentação, Universidade Estadual de Campinas, Campinas, Brazil). If a food/drink reported by the adolescent was not available in the Brazilian table, data from USDA National Nutrient Database for Standard Reference, Release 21 were used (United States Department of Agriculture. Food search for Window, version 1.0, database SR20. http://www.ars. usda.gov/nutrientdata, accessed on Sep/2008). These food composition tables were used for the $24 \mathrm{hR}$ and FFQ. Means were calculated for energy intake reported in the three days of $24 \mathrm{hR}$ and data were analyzed in an electronic version of a locally-built software aimed at analyzing $24 \mathrm{hR}$ (ADS Nutri - Nutritional system - 9th version; Fundação de Apoio Universitário, Universidade Federal de Pelotas, Pelotas, Brazil). A do-file was created in the Stata 9.0 software (Stata Corp., College Station, USA) to analyze energy and macronutrients of all foods/drinks included in the FFQ. The energy intake was obtained through the sum of calories derived from macronutrients. The frequency of each food/drink in a standard portion was multiplied by the macronutrient content and it was summed in calories by multiplying by 4,4 and 9 for each gram of protein, carbohydrate and lipid, respectively.

Energy expenditure was predicted using an equation developed by Trost et al. 11 in which counts per minute and body mass were included in a multiple regression to estimate calories.

Statistical analyses were performed in Stata 9.0. Information about adolescents whose daily intake was below the $1^{\text {st }}$ or above the 99th percentile of the sample itself was excluded in order to avoid over or underestimation of the distribution of energy and macronutrients ${ }^{12}$. Results are presented through descriptive statistics, including means, medians, standard deviations and interquartile ranges. Bland \& Altman plots were used in the analyses to compare methods of assessment energy intake and expenditure.

\section{Results}

A subsample of 183 adolescents from the births cohort (96.8\% of this study sample), answered three $24 \mathrm{hR}$ and the FFQ. Mean age was 13.4 years $( \pm 0.3)$; the youngest was aged 12.7 and the oldest 14 years. This subsample was equally distributed by sex and the proportions by categories of birth weight and maternal schooling in 1993 were similar when compared to the same groups of these variables for the whole cohort (Table 1).

Table 2 presents means of energy and macronutrients intake according to each dietary assessment method. Energy intake was overestimated by FFQ compared to $24 \mathrm{hR}$; this due to overestimation of all macronutrients instead of any specific one (mean differences of carbohydrate: $79 \pm$ 132; protein: $32 \pm 39$; lipid: $18 \pm 38$ ). However, the proportion of macronutrients in relation to total calories was similar in both methods.

Average energy expenditure estimated by accelerometers was $2,356 \mathrm{kcal}( \pm 460)$ and the median was $2,303 \mathrm{kcal}$ (inter-quartile range IQR = 548). When FFQ was used as dietary assessment method, the ratio of energy intake and expenditure was 1.13 and it was 0.87 if $24 \mathrm{hR}$ was compared with energy expenditure measured through the accelerometer.

Bland \& Altman analysis was performed for energy intake measured by both dietary methods (24hR and FFQ). The mean difference (592 \pm $929 \mathrm{cal} /$ day) between the two methods reflected a considerable amount of over-reporting by FFQ compared to $24 \mathrm{hR}$, and the limits of agreement ranged from $-1,267$ to 2,450cal/day $\pm 2 \mathrm{SD}$ (Figure 1). The overestimation of FFQ in relation to $24 \mathrm{hR}$ seems greater if the energy intake is higher.

The comparison between energy intake and expenditure is presented in Figures 2 and 3. The Bland \& Altman plot for energy intake measured by FFQ and energy expenditure show that the overestimation of FFQ in relation to energy expenditure also seems greater if the energy intake is higher, however, the mean difference between FFQ and accelerometer ( $357 \pm 968 \mathrm{cal} /$ day) was lower than the difference of both dietary methods. In spite of the lower difference, the limits of agreement ranged from $-1,581$ to $2,294 \pm 2$ SD (Figure 2). Otherwise, the underestimation of energy intake measured by $24 \mathrm{hR}$ compared to energy expenditure measured by accelerometers does not seem to be related to the amount of energy intake, taking into account the distribution of the subjects in any energy intake and not only 
Characteristics of the original cohort and the sub-sample included in this analysis. 1993 Pelotas (Brazil) birth cohort study, 2006-2007.

\begin{tabular}{lcc}
\hline Variables & Original cohort & Sub-sample \\
& $\mathbf{n}(\%)$ & $(\%)$ \\
\hline Sex & & $91(49.7)$ \\
$\quad$ Male & $2,580(49.2)$ & $92(50.3)$ \\
$\quad$ Female & $2,667(50.8)$ & $18(9.8)$ \\
Birth weight (g) & & $115(62.8)$ \\
$<2,500$ & $510(9.8)$ & $50(27.3)$ \\
$2,500-3,499$ & $3,361(64.2)$ & $5(2.7)$ \\
$\geq 3,500$ & $1,361(26.0)$ & $49(26.9)$ \\
Maternal schooling at birth (years) & & $85(46.4)$ \\
0 & $134(2.6)$ & $44(24.0)$ \\
$1-4$ & $1,338(25.5)$ & $183(100.0)$ \\
$5-8$ & $2,424(46.2)$ & \\
\hline 9
\end{tabular}

* There is less than $0.5 \%$ of missing information.

Mean, median and standard deviation (SD) and inter-quartile range (IQR) of daily energy and macronutrients intake estimated by 24-hour recall (24hR) and food-frequency questionnaire (FFQ) in adolescents. 1993 Pelotas (Brazil) birth cohort study, 2006-2007.

\begin{tabular}{|c|c|c|c|c|c|c|c|c|}
\hline & \multicolumn{4}{|c|}{$24 \mathrm{hR}$} & \multicolumn{4}{|c|}{ FFQ } \\
\hline & Mean & Median & SD & IQR & Mean & Median & SD & IQR \\
\hline Energy (kcal) & 2,059 & 1,990 & 669 & 757 & 2,664 & 2,563 & 899 & 1,281 \\
\hline Carbohydrate (g) & 305 & 298 & 97 & 125 & 385 & 372 & 131 & 104 \\
\hline Protein (g) & 70 & 65 & 27 & 32 & 101 & 97 & 40 & 53 \\
\hline Lipid (g) & 61 & 56 & 29 & 31 & 80 & 72 & 34 & 50 \\
\hline Carbohydrate (\%) & 59.9 & 60.6 & 7.5 & 11.5 & 58.3 & 58.3 & 6.7 & 10.1 \\
\hline Protein (\%) & 13.8 & 13.4 & 3.1 & 4.1 & 15.2 & 14.9 & 3.2 & 3.9 \\
\hline Lipid (\%) & 26.3 & 25.7 & 6.3 & 8.8 & 26.5 & 26.6 & 4.8 & 7.5 \\
\hline
\end{tabular}

those who had higher energy intake as was observed in relation to the overestimation of FFQ. The mean difference was $-278 \pm 714 \mathrm{cal} /$ day and the limits of agreement ranged from $-1,707$ to $1,151 \pm 2$ SD (Figure 3).

\section{Discussion}

The present study described the methods of dietary assessment used in a subsample from the 1993 Pelotas (Brazil) birth cohort and compared the results of energy intake with energy expendi- ture measured by accelerometry. The measurement of diet during adolescence in our cohort is very important, if we are able to investigate its long term consequences for health. In addition, the description of the differences between the two methods of dietary assessment adds quantitative information about food intake of these adolescents taking into account that qualitative data have been previously published 13. However, a limitation of the present study is that the methods were compared only in energy, while a comparison including other nutrients could be more interesting. 
Figure 1

Bland \& Altman plot of differences between daily energy intake measured by food frequency questionnaire (FFQ) and 24-hour recall (24hR) among adolescents from the 1993 Pelotas (Brazil) birth cohort study.

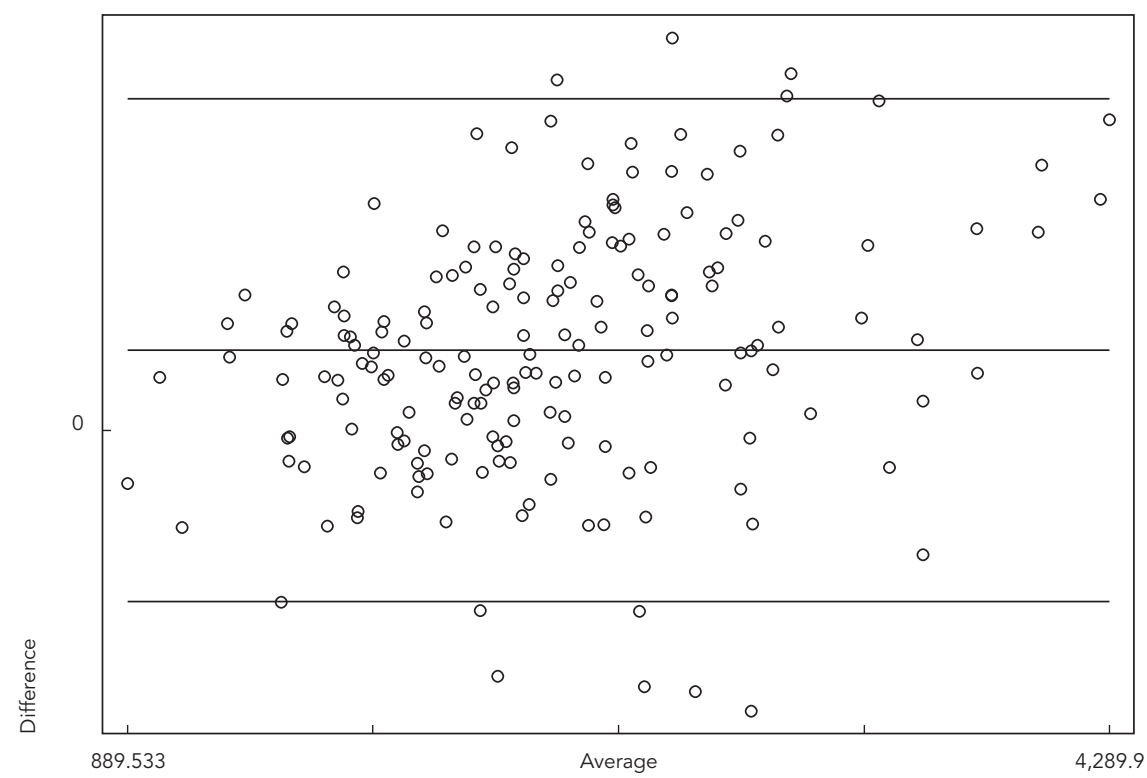

Figure 2

Bland \& Altman plot of differences between daily energy intake measured by food frequency questionnaire (FFQ) and energy expenditure estimated by accelerometer among adolescents from the 1993 Pelotas (Brazil) birth cohort study.

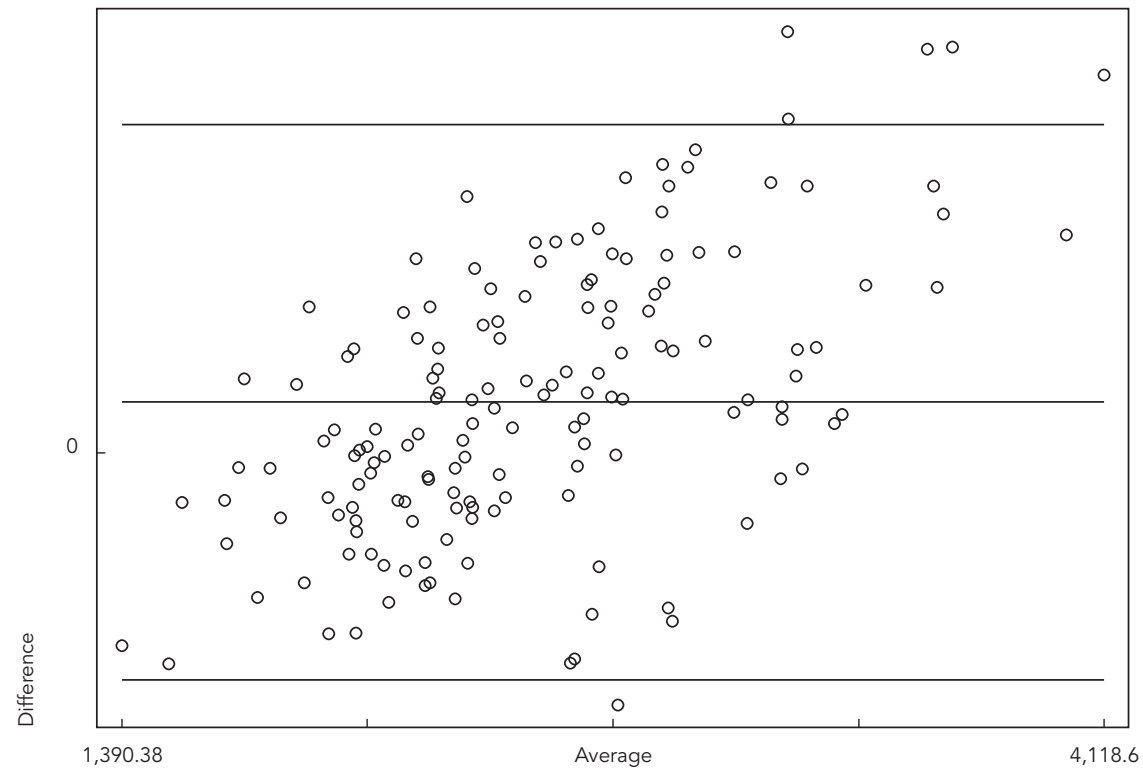


Bland \& Altman plot of differences between daily energy intake measured by 24-hour recall (24hR) and energy expenditure estimated by accelerometer among adolescents from the 1993 Pelotas (Brazil) birth cohort study.

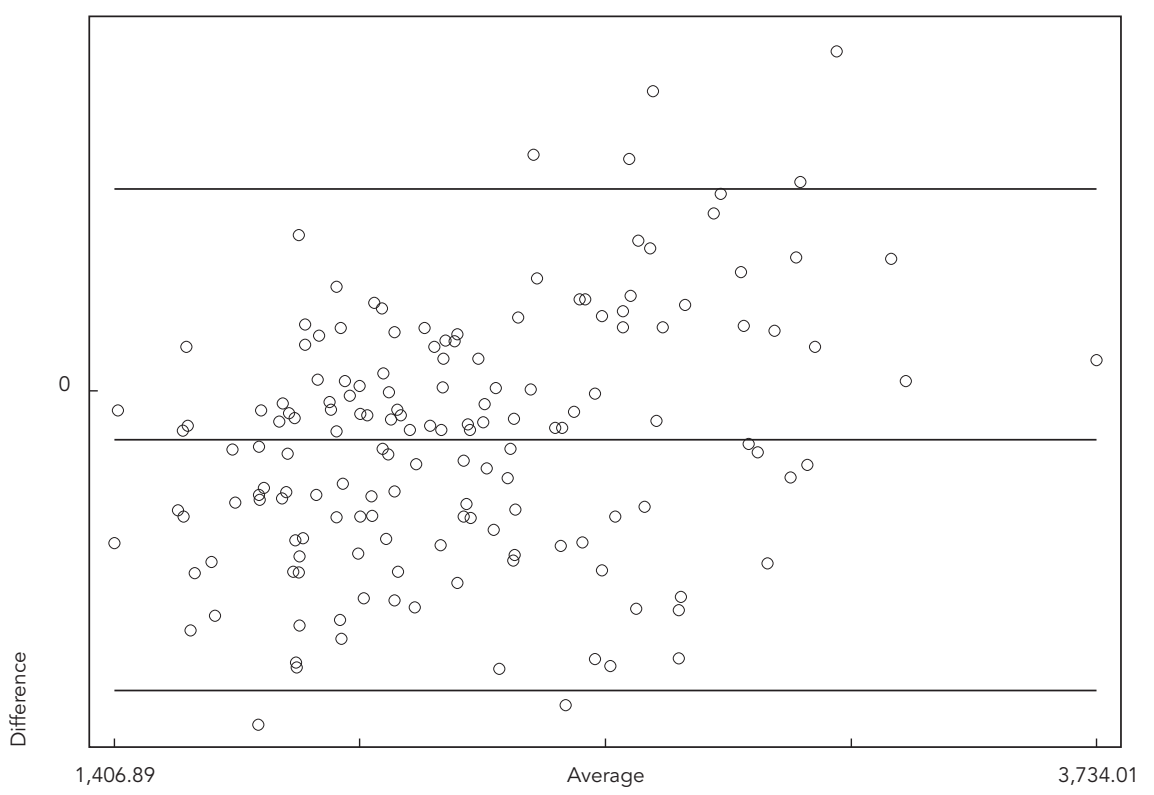

Validation studies of energy intake are extensively conducted in Europe and the USA 2,3. We found 27 studies published in which the food intake of the Brazilian population was considered, and the validity of FFQ was assessed in most of them. While adults were investigated in the majority of these validation studies, children and adolescents were the target population in eleven papers. When excluding those with children up to 10 years of age, six studies were revised. The first was published in 199810 aiming to evaluate associated factors with overweight/obesity in adolescents and used a FFQ based on repeated 24hR. However, these methods were not compared and validity measurements (or reproducibility) were not presented. In two other studies 14,15 , FFQ were applied twice, aiming to assess the repeatability of the measurements. Although these studies presented several differences and the validity was not assessed, both concluded that FFQ showed acceptable reproducibility and may be applied with adolescents. The relative validity of the estimates of energy was assessed in just one study including adolescents 16 (repeatability of the FFQ was previously assessed) 14 and the results showed high correlation in the comparison between FFQ and the average of three $24 \mathrm{hR}$ applied 45 days apart. Another study that included female adolescents 17 described the means of energy and other nutrients for each method applied (24hR, three day dietary records and purchase list), and concluded that the three methods presented measurement errors. A comparison of a short FFQ and the serum cholesterol was also found in the Brazilian studies with adolescents 18 . This study presented the largest sample, including 539 subjects aged 12 to 19 years from public schools and the results showed that the short FFQ was not a predictor of cholesterol concentration. To sum up, none of the previous measurements were able to identify the true value of energy intake among Brazilian adolescents.

Data from the present study showed a great difference in energy intake between the two methods of dietary assessment. At the same time, energy expenditure estimated by accelerometer was higher than energy intake measured by $24 \mathrm{hR}$ and lower than energy intake measured by FFQ. There is just one other Brazilian study comparing energy intake and expenditure ${ }^{19}$. Energy expenditure was estimated by oxygen uptake $\left(\mathrm{VO}_{2}\right)$ and respiratory exchange ratio (RER) in 38 women submitted to spirometry and heart rate monitor- 
ing. Energy intake was estimated by a seven-day food diary. Seventeen women (49\%) underreported their energy intake and this was partially explained by women reporting eating less than usual, making mistakes in portion size estimation and complaining about having to record everything which was eaten 19. Underreported energy intake was also observed in other studies using accelerometer to measure energy expenditure 20,21. However, these studies included small samples of adults. In addition, the seven-day food diary was the dietary assessment method used in these studies. If energy expenditure was assessed by DLW and compared with energy intake, underreporting was also documented in several studies from the USA and Europe ${ }^{3}$. The DLW technique has been used to identify components of underreporting, for instance under-eating ${ }^{22}$. Although less frequent than underreporting, over reporting may also occur 3 .

The assessment of over- and underreporting is based on the assumption that the energy intake must be equal to expenditure when body weight is stable. This assumption is considered if energy expenditure was measured by both DLW and accelerometer ${ }^{3}$. The present study included a subsample of adolescents whose nutritional status was previously assessed 23 and the measurements of energy intake and expenditure were obtained in the same week for $24 \mathrm{hR}$ and accelerometer. Although FFQ is related to a one year period, the comparison among the three methods was based on daily energy intake or expenditure.

According to the assumption that the energy intake is equal to expenditure, we can consider that the adolescents from the 1993 Pelotas (Brazil) birth cohort study over- or underestimated their intakes if FFQ or $24 \mathrm{hR}$, respectively, were used as dietary assessment methods. While different methods of measuring energy intake have their own limitations, the comparison with measurements of energy expenditure is interesting due to the presence of different sources of errors and bias. However, an estimate calculated by a predictive equation using measurements of body mass and counts per minute from the accelerometer may not be considered as a gold standard to measure energy expenditure.

In nutritional epidemiology, another aspect to be considered in the validation process is related to the differences among the techniques of analyses used in the studies. Most validation studies have used a correlation coefficient to assess the relationship between the intakes obtained from the two methods $1,2,3,6,24$. In the 168 validation studies (representing $83 \%$ of all) included in a review 2 , the correlation coefficient was used, being the most common statistical method. In 21 of the
27 Brazilian studies the correlation coefficient was also used. However, it has been recognized for a long time that the use of the correlation coefficient is inappropriate 25,26 due to the fact that it measures the strength of association and not the agreement between measurements 26 . So, considering that the first step to compare two numerical variables would be a scatter plot, it could be one of the reasons for many researchers to have used the correlation coefficient in validation studies of energy intake. The comparison with previous studies could be another reason to use the correlation coefficient. Other statistical methods (test on the means or medians, intra-class correlation, regression analysis, crossclassification, mean and standard deviation of the difference, analysis of categories, methods of triads and multivariate regression models) are also used in nutritional epidemiology. However, there is a lack of consensus on appropriate statistical methods for assessing the validity of dietary measurements 22 . Otherwise, statistical analysis of mean and standard deviation of the difference described by Bland \& Altman 25 is considered as an appropriate analysis to method comparison studies, in which two different measurements of the same underlying (true) value are compared 26.

While most studies in nutritional epidemiology have used the correlation coefficient in the analysis, five Brazilian studies using Bland \& Altman plots were identified 15,16,27,28,29. Two of these were conducted with adolescents and only reliability was assessed by Bland \& Altman analysis 14,15. Regression analysis has also been used in nutritional epidemiology as a calibration method 2 . However, as proposed by Bland \& Altman, using a new method to predict an old one is not the purpose of a comparitive study 30 .

Questions involving problems and limitations of dietary assessment studies have been published recently 31,32 . The focus was on the dietary assessment 33 and, specifically on micronutrient intakes 34 . Some questions in dietary assessment at any life stage, such as skills to provide a reliable report of dietary intake were discussed 34 . Although, in the present study, dietary methods were applied to adolescents, recipes and cooking methods were also asked to the person who usually prepares the meals. It is suggested that the use of surrogate reporters is unnecessary for subjects above 11 to 12 years of age, though some details may still need to be obtained from others, for example, types of spread, milk and cooking methods 35 . Recently, technology in dietary assessment has been proposed and adolescents, using a disposable camera, have taken pictures of the food they have eaten 36 . This method was more motivating than self-reporting. Considering 
that in the $24 \mathrm{hR}$, the adolescent has to remember everything that was eaten and in the FFQ, a list of foods is read to them, it is possible that more food items were recalled through this method, evidence that is confirmed in the findings of the present study.

In summary, this paper describes two methods of dietary assessment in a sub-sample of a birth cohort. In spite of the great differences between energy intakes from both methods, lower differences were observed when these dietary methods were compared to the measurement of energy expenditure. Taking into account that the true value is unknown, these results suggest that more than one method should be used if the main objective of the study is to estimate energy intake. We hope the findings of this paper may be useful for researchers interested in the investigation of the effects of early diet on the occurrence of chronic diseases.

\section{Resumo}

O objetivo do estudo foi descrever e comparar dois métodos de avaliação de consumo calórico e uma medida de gasto energético aplicados em adolescentes de uma coorte de nascimentos. Em uma subamostra da coorte de 1993 de Pelotas, Rio Grande do Sul, Brasil, acompanhada em 2006-2007, informações sobre consumo calórico foram obtidas através de questionário de frequência alimentar (QFA) e três recordatórios de 24 horas (R24h), enquanto gasto energético foi avaliado por acelerômetro. Gráficos de Bland \& Altman foram usados na comparação dos métodos. A diferença média entre QFA e R24h foi $592 \pm 929 \mathrm{cal} /$ dia. Ao comparar com gasto energético, o consumo foi superestimado se medido pelo QFA (357 \pm 968cal/dia) e subestimado pelo $R 24 h$ ( $-278 \pm 714$ calldia). Apesar da grande diferença no consumo, menores diferenças foram observadas quando os dois métodos foram comparados ao gasto energético.

Ingestão de Energia; Nutrição do Adolescente; Metabo lismo Energético; Estudos de Validação

\section{Contributors}

D. P. Gigante was involved in all stages of the study from planning to article write up. F. F. Reichert, M. B. Neutzling and M. F. A. Vieira contributed to all stages of the study from planning to article write up. P. C. Hallal, M. C. F. Assunção, C. L. Araújo and A. M. B. Menezes contributed towards the planning of the study and the revision of the article. R. V. Souza supervised data collection and reviewed the article.

\section{Acknowledgments}

The cohort study is supported by the Wellcome Trust. The initial phases of the cohort study were financed by the European Union, Brazilian Nation Program for Centers of Excellence (PRONEX), and by the Brazilian Ministry of Health. The current study also received support from the National Research Council (CNPq). 


\section{References}

1. Nelson M. The validation of dietary assessment In: Margetts BM, Nelson M, editors. Design concepts in nutritional epidemiology. London: Oxford University Press; 1997. p. 241-72.

2. Cade J, Thompson R, Burley V, Warm D. Development, validation and utilisation of food-frequency questionnaires: a review. Public Health Nutr 2002; 5:567-87.

3. Livingstone MB, Black AE. Markers of the validity of reported energy intake. J Nutr 2003; 133 Suppl 3:895S-920S.

4. Trost SG. Objective measurement of physical activity in youth: current issues, future directions. Exerc Sport Sci Rev 2001; 29:32-6.

5. St-Onge M, Mignault D, Allison DB, Rabasa-Lhoret R. Evaluation of a portable device to measure daily energy expenditure in free-living adults. Am J Clin Nutr 2007; 85:742-9.

6. Victora CG, Araújo CLP, Menezes AMB, Hallal PC, Vieira MF, Neutzling MB, et al. Methodological aspects of the 1993 Pelotas (Brazil) birth cohort study. Rev Saúde Pública 2006; 40:39-46.

7. Victora CG, Hallal PC, Araújo CL, Menezes AM, Wells JC, Barros FC. Cohort profile: the 1993 Pelotas (Brazil) birth cohort study. Int J Epidemiol 2008; 37:704-9.

8. Reichert FF, Menezes AM, Wells JC, Ekelund U, Rodrigues FM, Hallal PC. A methodological model for collecting high-quality data on physical activity in developing settings: the experience of the 1993 Pelotas (Brazil) birth cohort study. J Phys Act Health 2009; 6:360-6.

9. Cole TJ. Sampling, study size, and power In: Margetts BM, Nelson M, editors. Design concepts in nutritional epidemiology. London: Oxford University Press; 1997. p. 64-86.

10. Fonseca VM, Sichieri R, Veiga GV. Fatores associados à obesidade em adolescentes. Rev Saúde Pública 1998; 32:541-9.

11. Trost SG, Way R, Okely AD. Predictive validity of three ActiGraph energy expenditure equations for children. Med Sci Sports Exerc 2006; 38:380-7.

12. Molina MC, Bettiol H, Barbieri MA, Silva AA, Conceição SI, Dos-Santos JE. Food consumption by young adults living in Ribeirao Preto, SP 2002/2004. Braz J Med Biol Res 2007; 40:1257-66.

13. Neutzling MB, Araújo CLP, Vieira MF, Hallal PC, Menezes AMB. Freqüência de consumo de dietas ricas em gordura e pobres em fibra entre adolescentes. Rev Saúde Pública 2007; 41:336-42.

14. Marchioni DML, Voci SM, Lima FEL, Fisberg RM, Slater B. Reproducibility of a food frequency questionnaire for adolescents. Cad Saúde Pública 2007; 23:2187-96.

15. Araújo MC, Ferreira DM, Pereira RA. Reprodutibilidade de questionário semiquantitativo de freqüência alimentar elaborado para adolescentes da Região Metropolitana do Rio de Janeiro, Brasil. Cad Saúde Pública 2008; 24:2775-86.
16. Slater B, Philippi ST, Fisberg RM, Latorre MR. Validation of a semi-quantitative adolescent food frequency questionnaire applied at a public school in Sao Paulo, Brazil. Eur J Clin Nutr 2003; 57:629-35.

17. Barbosa KB, Lima Rosado LE, Franceschini SC, Priore SE. Instrumentos de inquérito dietético utilizados na avaliação do consumo alimentar em adolescentes: comparação entre métodos. Arch Latinoam Nutr 2007; 57:43-50.

18. Teixeira MH, Veiga GV, Sichieri R. Assessment of a short food frequency questionnaire as predictor of hypercholesterolemia in adolescents. Arq Bras Cardiol 2007; 88:66-71.

19. Scagliusi FB, Polacow VO, Artioli GG, Benatti FB, Lancha Jr. AH. Selective underreporting of energy intake in women: magnitude, determinants, and effect of training. J Am Diet Assoc 2003; 103:1306-13.

20. Goris AH, Meijer EP, Kester A, Westerterp KR. Use of a triaxial accelerometer to validate reported food intakes. Am J Clin Nutr 2001; 73:549-53.

21. Murakami K, Shimbo M, Fukino Y. Comparison of energy intakes estimated by weighed dietary record and diet history questionnaire with total energy expenditure measured by accelerometer in young Japanese women. J Nutr Sci Vitaminol (Tokyo) 2005; 51:58-67.

22. Gibson RS. Principles of nutritional assessment. 2nd Ed. Dunedin: Oxford Universtiy Press; 2005.

23. Vieira MFA, Araújo CLP, Neutzling MB, Hallal PC, Menezes AMB. Diagnosis of overweight and obesity in adolescents from the 1993 Pelotas Birth Cohort Study, Rio Grande do Sul State, Brazil: comparison of two diagnostic criteria. Cad Saúde Pública 2007; 23:2993-9.

24. Willett W. Nutritional epidemiology. New York: Oxford University Press; 1998.

25. Bland JM, Altman DG. Statistical methods for assessing agreement between two methods of clinical measurement. Lancet 1986; 1:307-10.

26. Kirkwood B, Sterne J. Essential medical statistics. Malden: Blackwell Publishing; 2003.

27. Haisma H, Coward WA, Albernaz E, Barros A, Victora CG, Wright A, et al. $2 \mathrm{H} 2 \mathrm{O}$ turnover method as a means to detect bias in estimations of intake of nonbreast milk liquids in breast-fed infants. Eur J Clin Nutr 2005; 59:93-100.

28. Scagliusi FB, Ferriolli E, Pfrimer K, Laureano C, Cunha CS, Gualano B, et al. Underreporting of energy intake in Brazilian women varies according to dietary assessment: a cross-sectional study using doubly labeled water. J Am Diet Assoc 2008; 108:2031-40.

29. Pereira GA, Genaro PS, Santos LC, Sarkis KS, Pinheiro MM, Szjenfeld VL, et al. Validation of a food frequency questionnaire for women with osteoporosis. J Nutr Health Aging 2009; 13:403-7.

30. Bland JM, Altman DG. Comparing two methods of clinical measurement: a personal history. Int J Epidemiol 1995; 24 Suppl 1:S7-14. 
31. Warren JM, Stephen AM. Dietary assessment at the end of life's spectrum. Eur J Clin Nutr 2009; 63 Suppl 1:S1-4.

32. Uauy R. The assessment of dietary adequacy based on nutrient intake data is a complex issue. Foreword. Br J Nutr 2009; 101 Suppl 2:S1.

33. Adamson AJ. Dietary assessment at the end of life's spectrum. Eur J Clin Nutr 2009; 63 Suppl 1:S5.

34. Serra-Majem L. Introduction. Dietary assessment of micronutrient intakes: a European perspective. Br J Nutr 2009; 101 Suppl 2:S2-5.
35. Emmett P. Workshop 2: the use of surrogate reporters in the assessment of dietary intake. Eur J Clin Nutr 2009; 63 Suppl 1:S78-9.

36. Winter J, Boushey CJ. Workshop 1: use of technology in dietary assessment. Eur J Clin Nutr 2009; 63 Suppl 1:S75-7.

Submitted on $23 /$ Oct/2009

Final version resubmitted on 13/Jan/2010

Approved on 04/Apr/2010 